Supplement of Hydrol. Earth Syst. Sci., 22, 5901-5917, 2018

https://doi.org/10.5194/hess-22-5901-2018-supplement

(C) Author(s) 2018. This work is distributed under

the Creative Commons Attribution 4.0 License.

(c) (1)

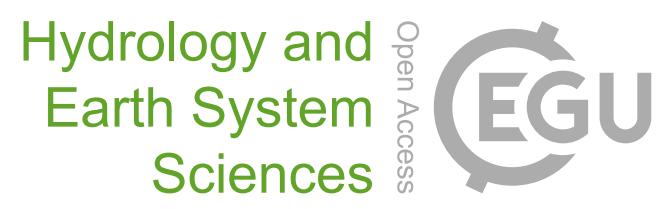

Supplement of

\title{
Do users benefit from additional information in support of operational drought management decisions in the Ebro basin?
}

Clara Liné et al.

Correspondence to: Clara Linés (c.lines@un-ihe.org)

The copyright of individual parts of the supplement might differ from the CC BY 4.0 License. 
Figure S1: Total benefit for different costs

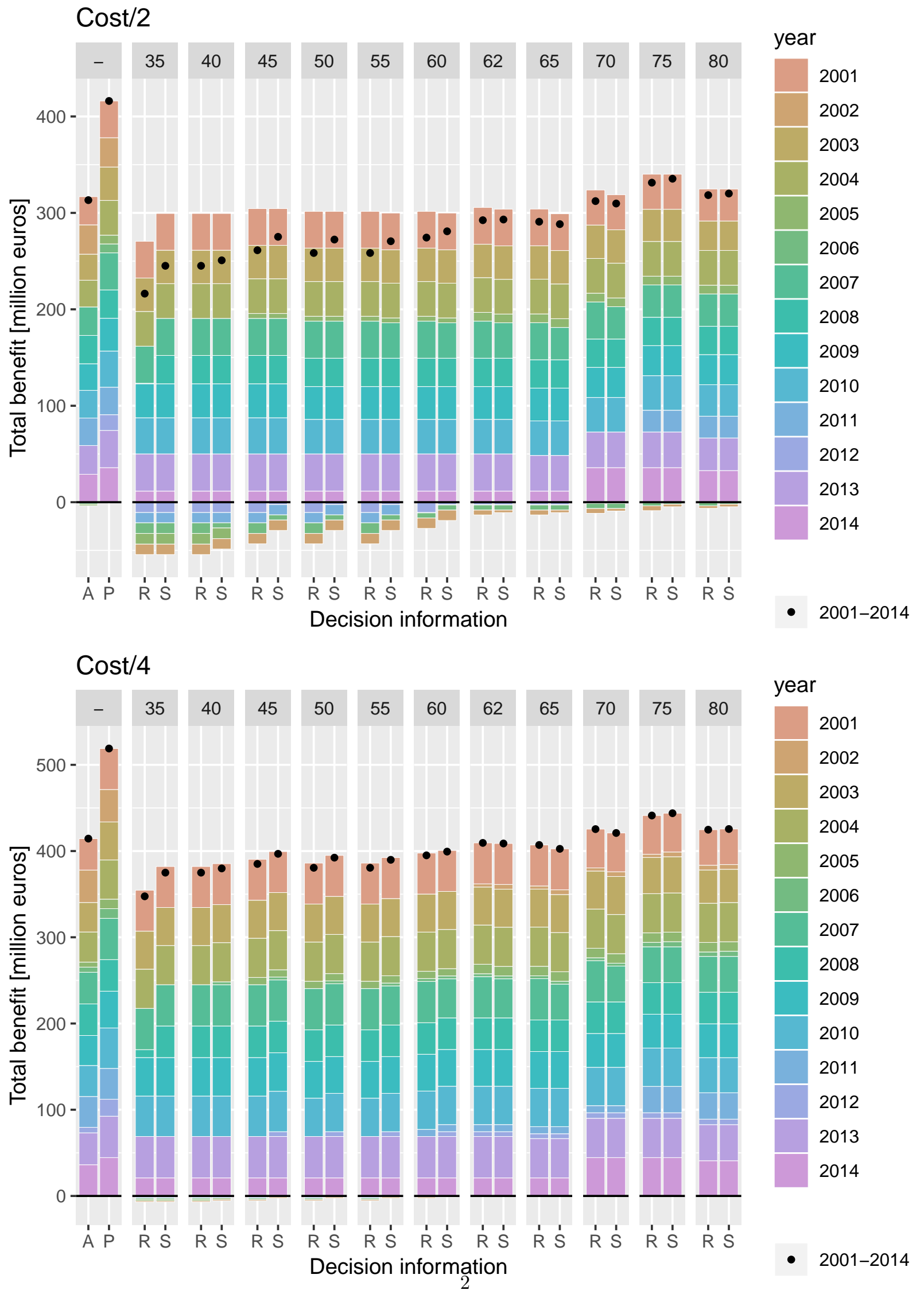




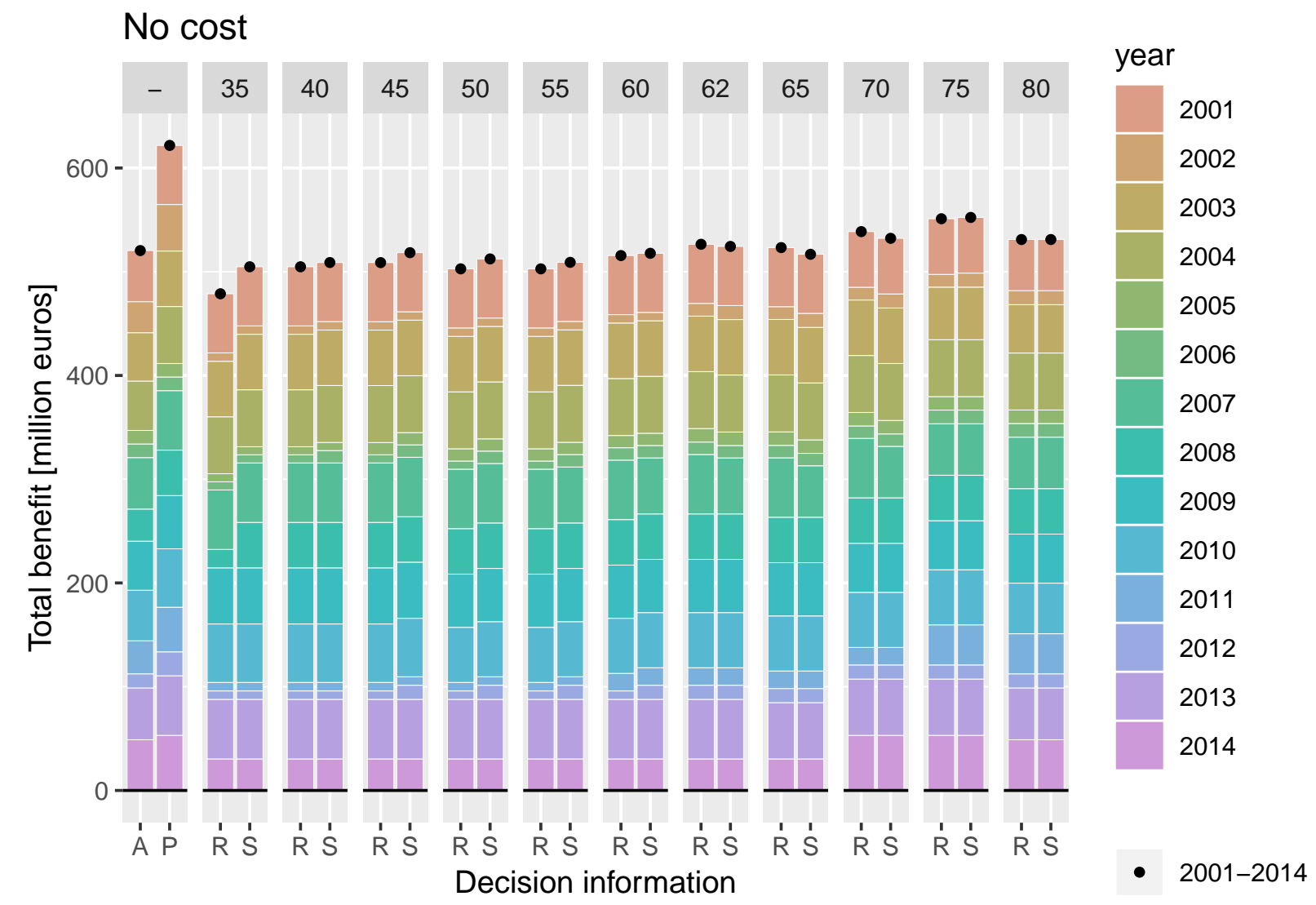




\section{Figure S2: Yearly relative value}

Yearly Relative Value for decisions informed by reservoir level alone (R) and with the addition of snow information (S) for the 10 sets of thresholds and the optimized thresholds (labelled as 62). When the uninformed decision results in the same benefit as the perfect information the Relative Value is -Infinite and is left blank in the plot.

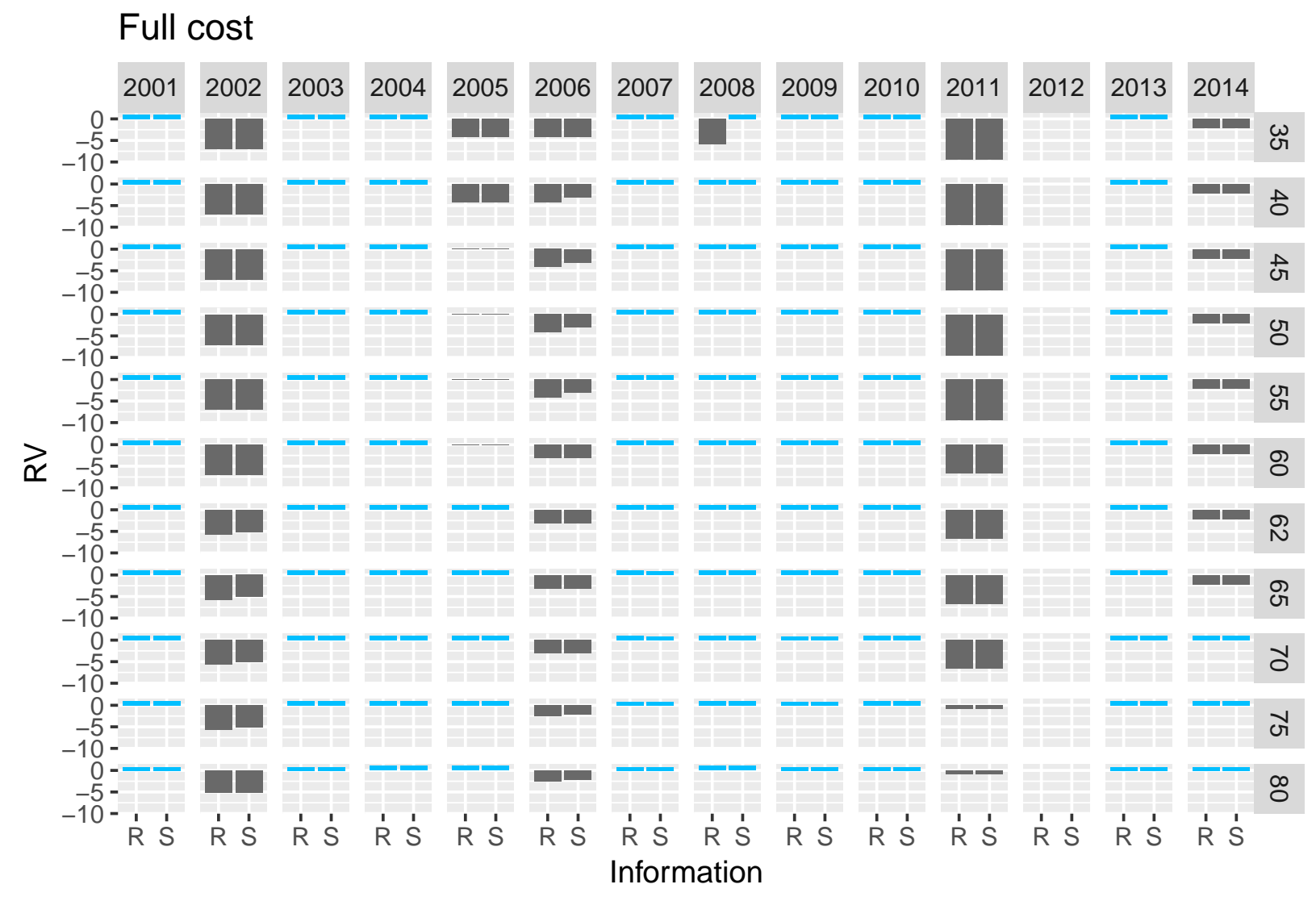




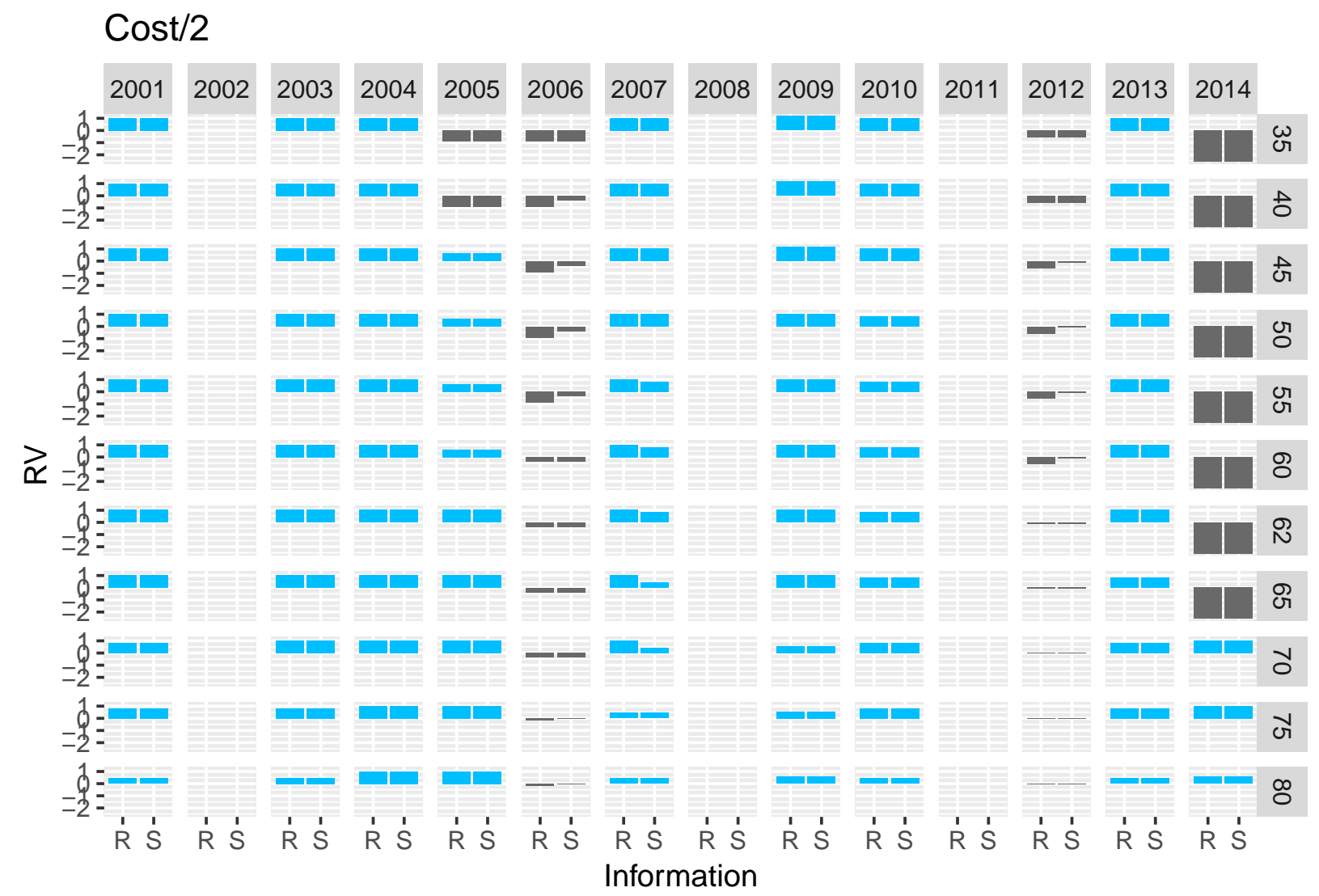




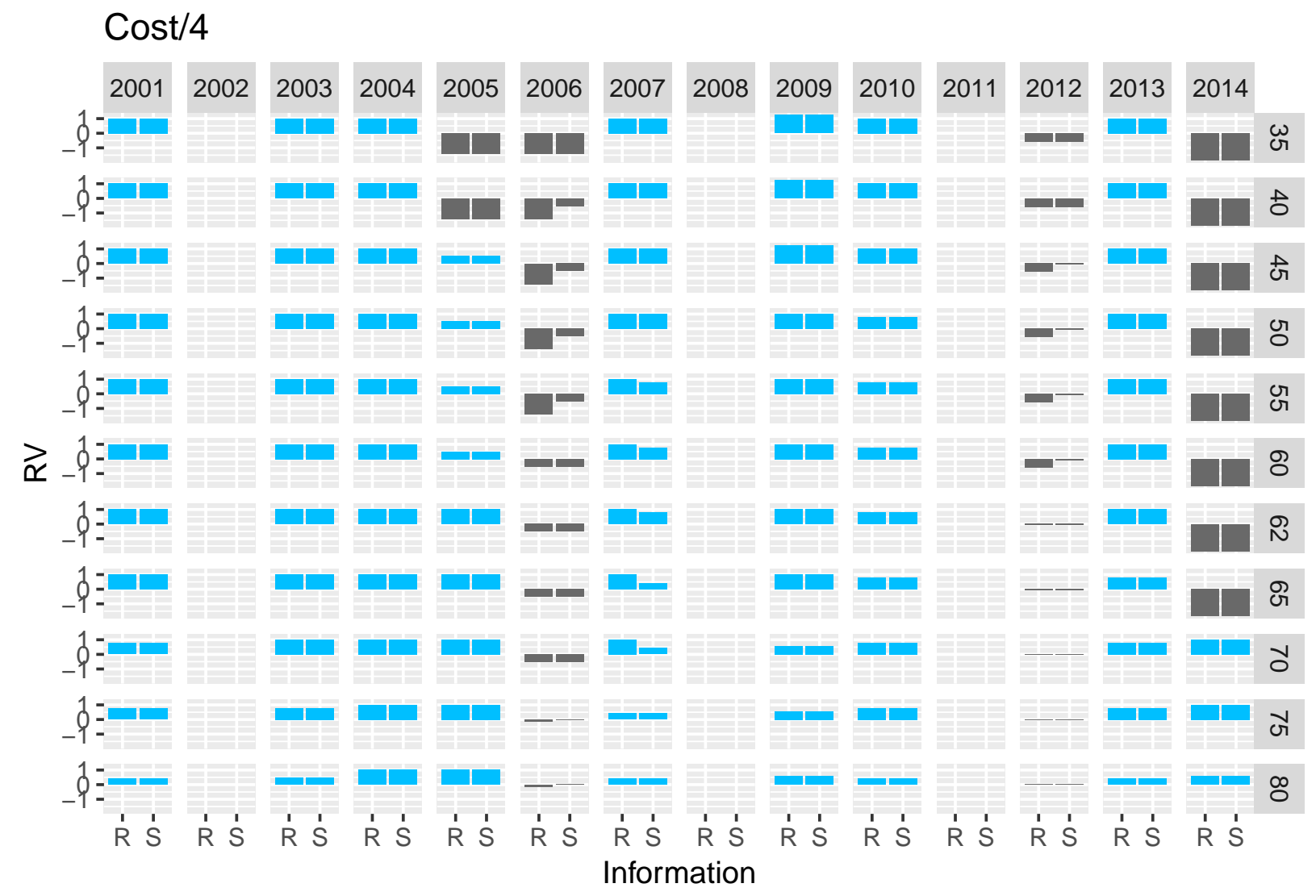




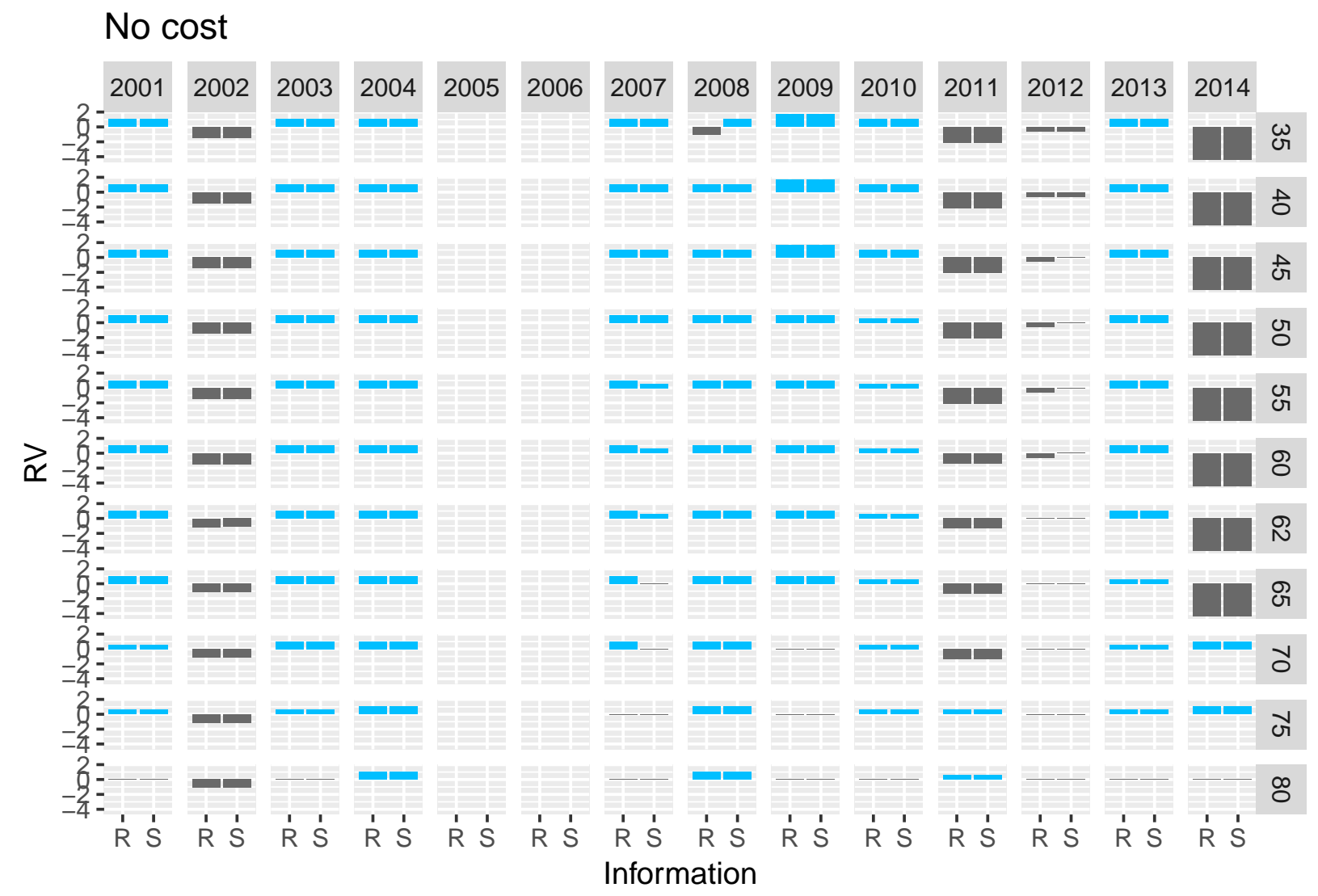




\section{Figure S3: Test with random snow values}

10 additional runs were performed with random snow values. The objective is to test if the improvements in the decisions observed when the model is run with additional information are indeed the result of better information and not a casual effect.

The first run (run 00) corresponds to MODIS snow data and the following runs (run 02-10) to the generated random data.

\section{(a) Snow values}

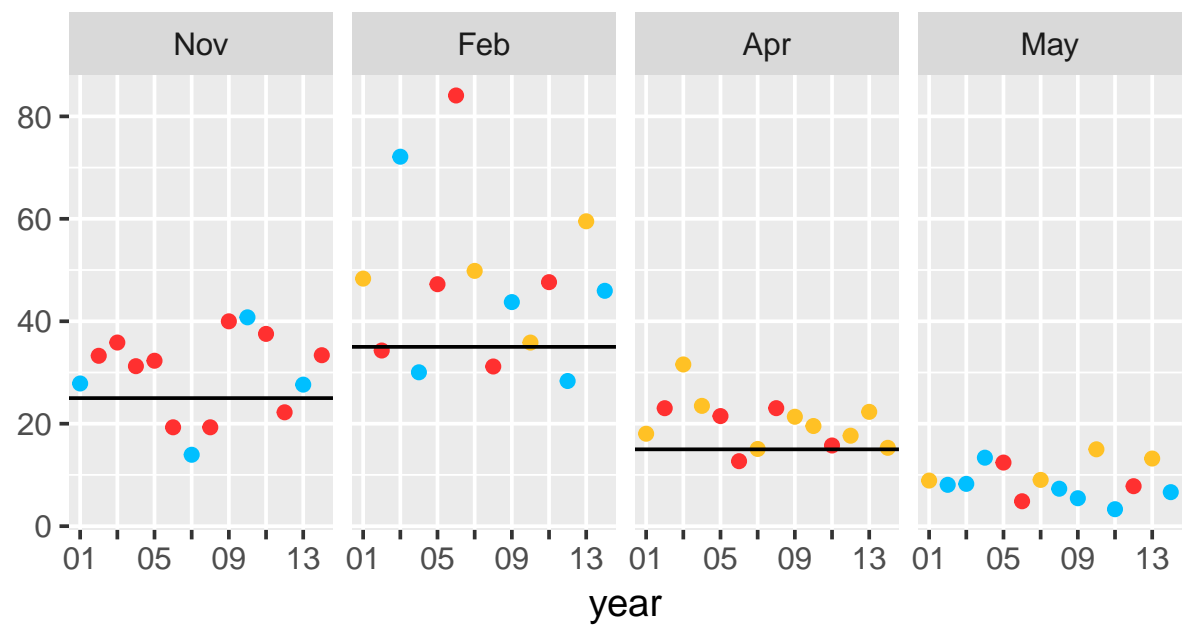

\section{thresholds}

\section{individual}

optimal course

- poor availability

- good availability

- indifferent
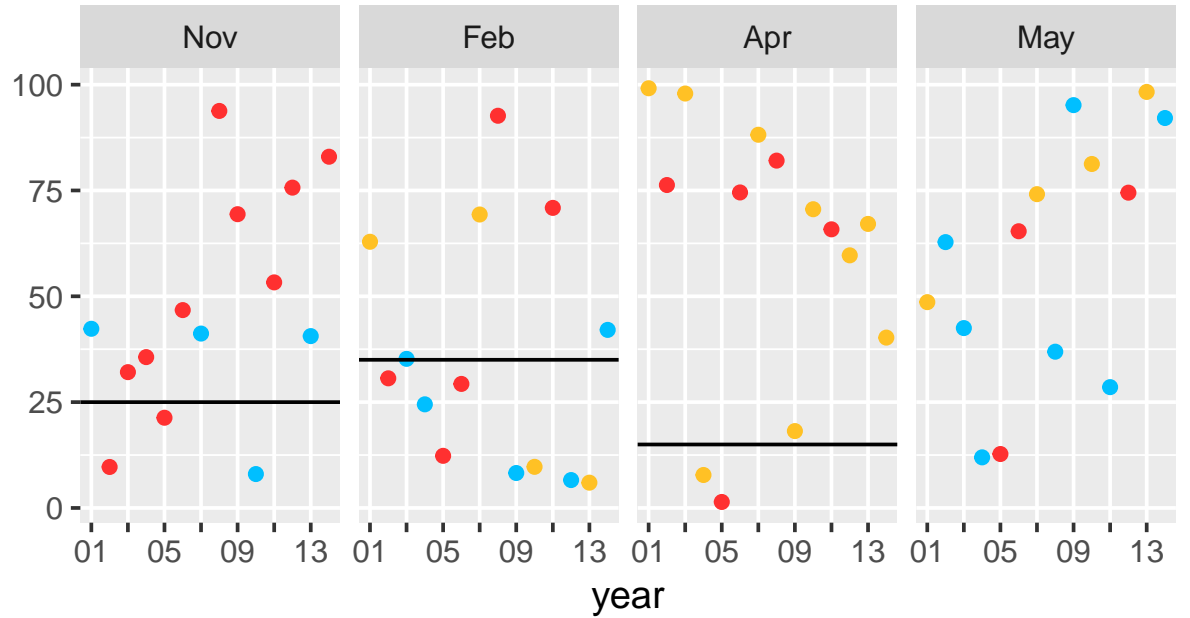

thresholds

- individual

optimal course

- poor availability

- good availability

- indifferent

\section{year}



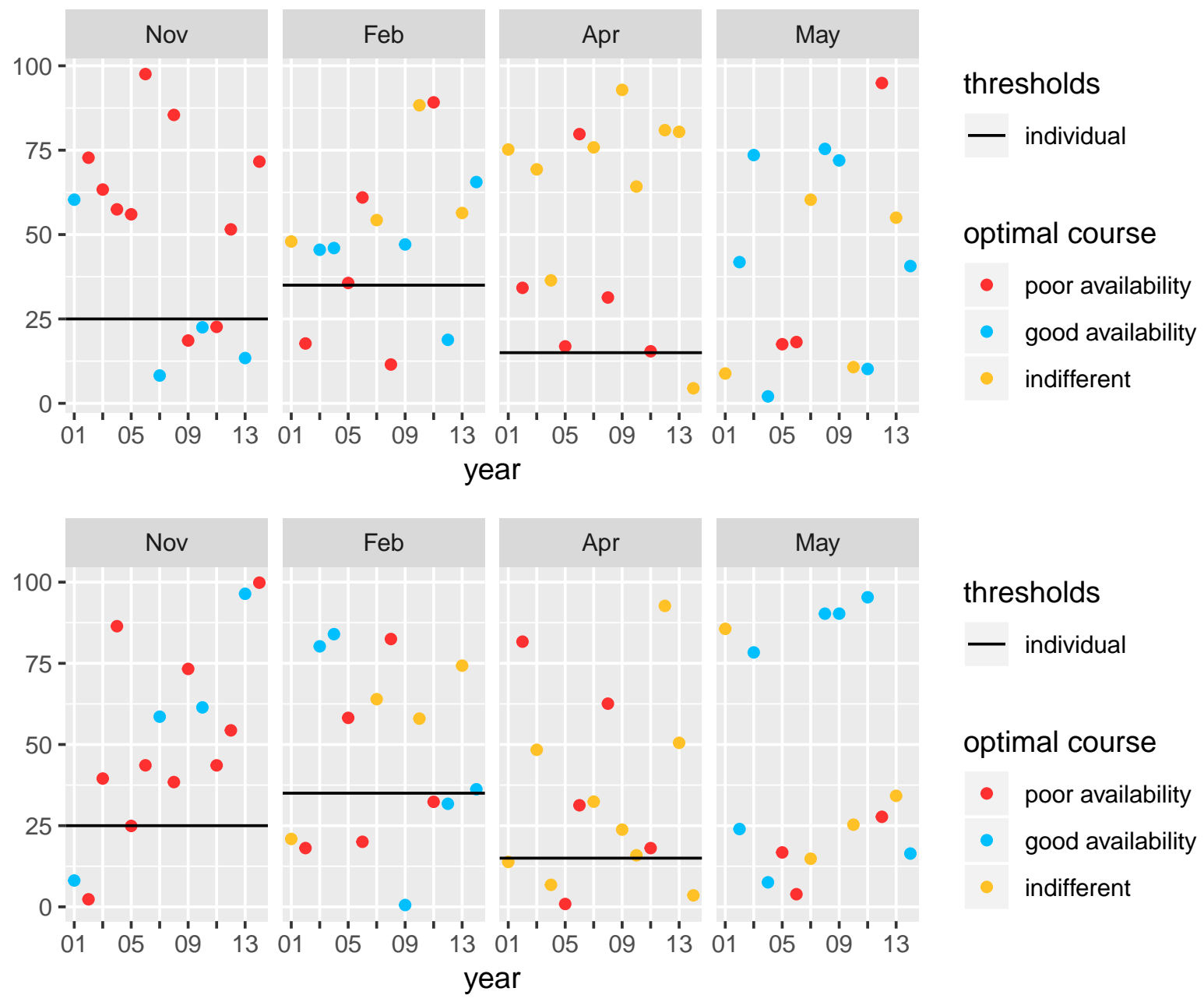

\section{thresholds}

— individual

\section{optimal course}

- poor availability

- good availability

- indifferent

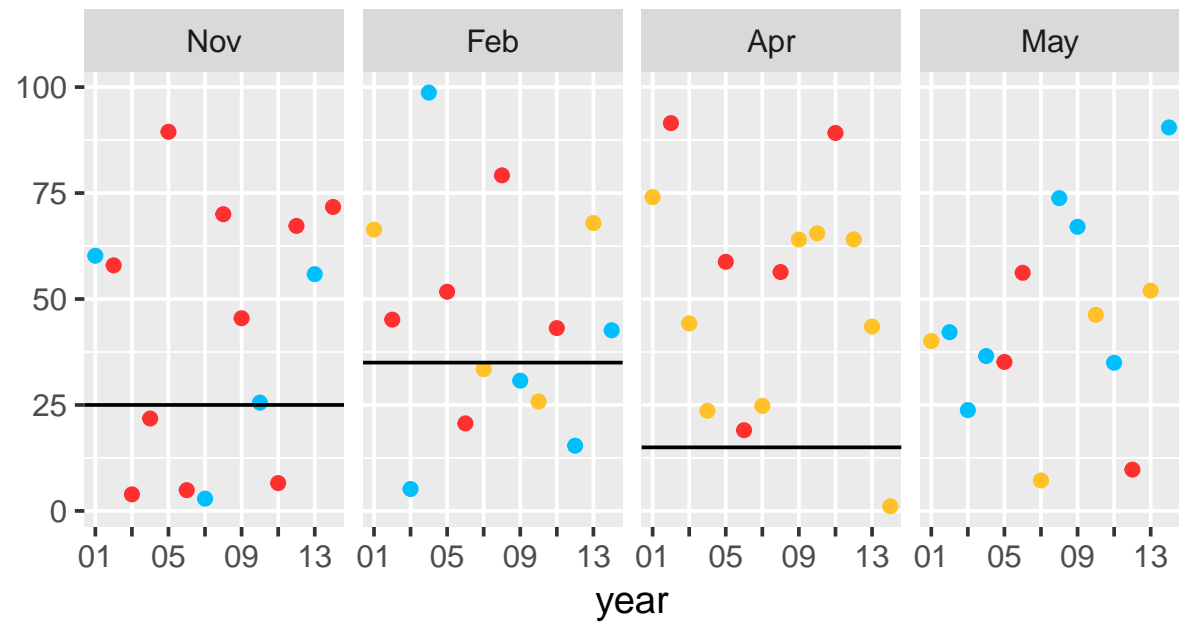

thresholds

— individual

optimal course

- poor availability

- good availability

- indifferent 


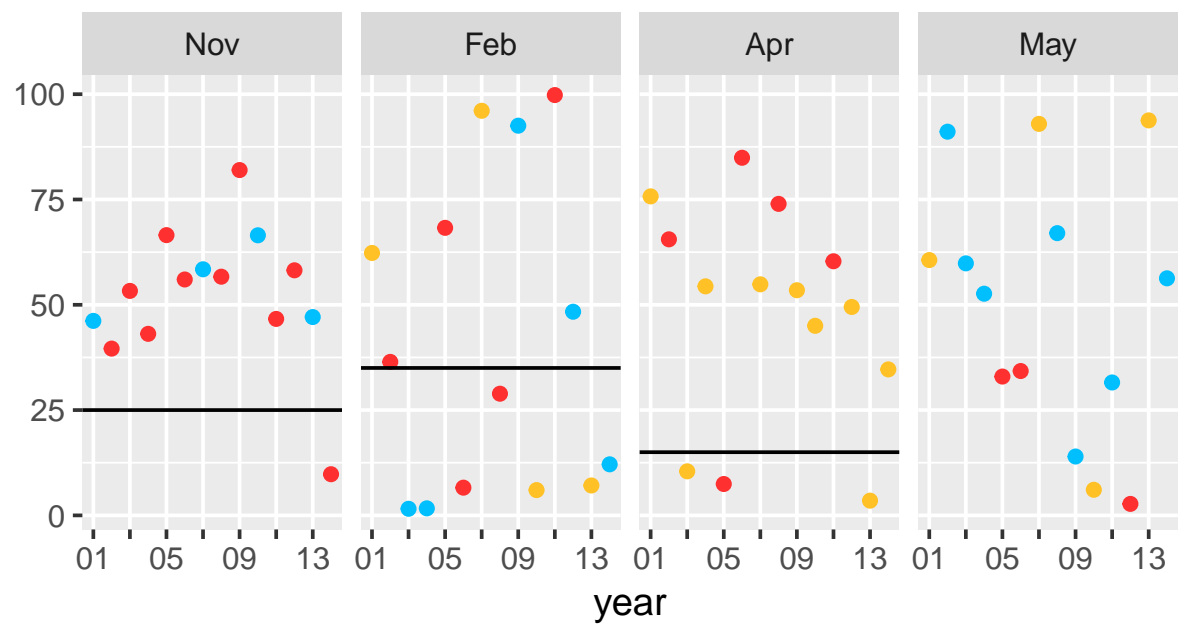

thresholds

— individual

optimal course

- poor availability

- good availability

- indifferent

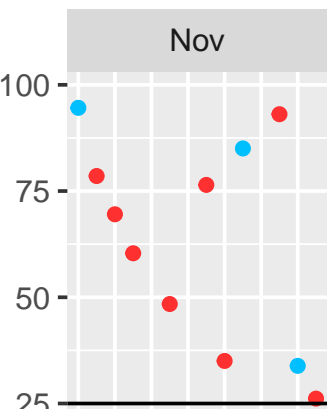

25
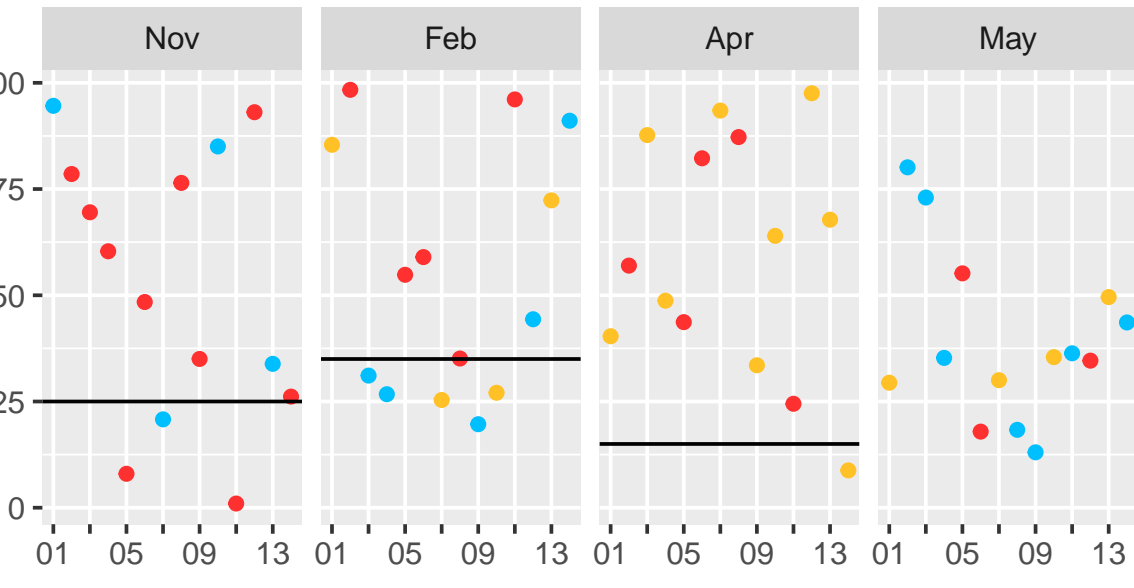

year

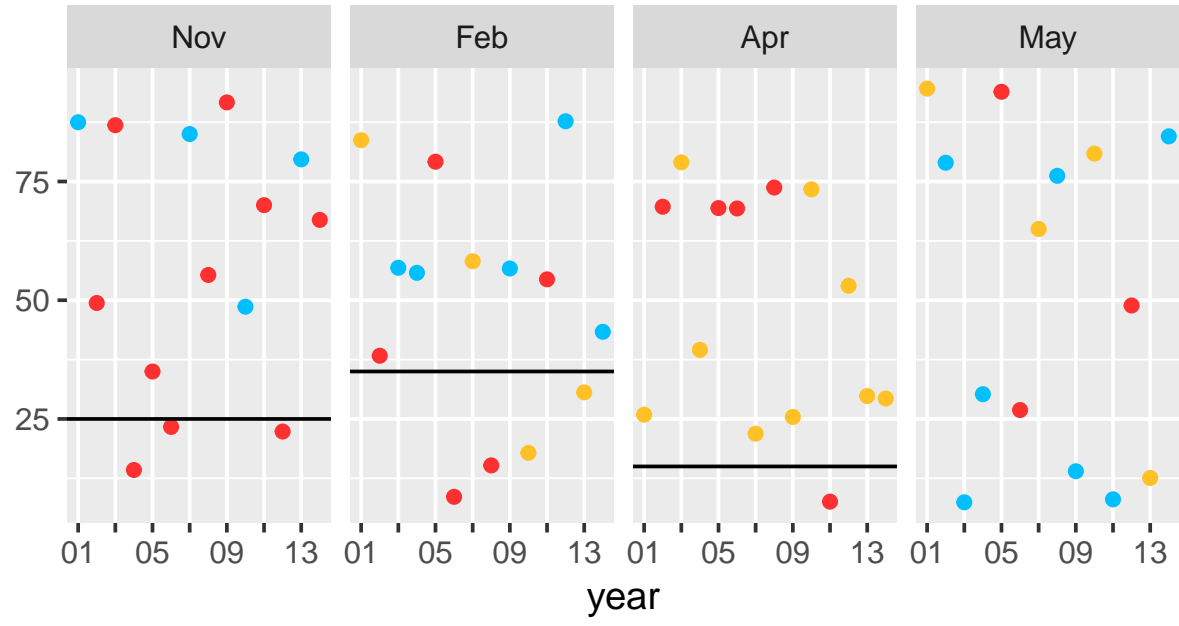

thresholds

- individual

optimal course

- poor availability

- good availability

- indifferent

\section{thresholds}

— individual

optimal course

- poor availability

- good availability

- indifferent 

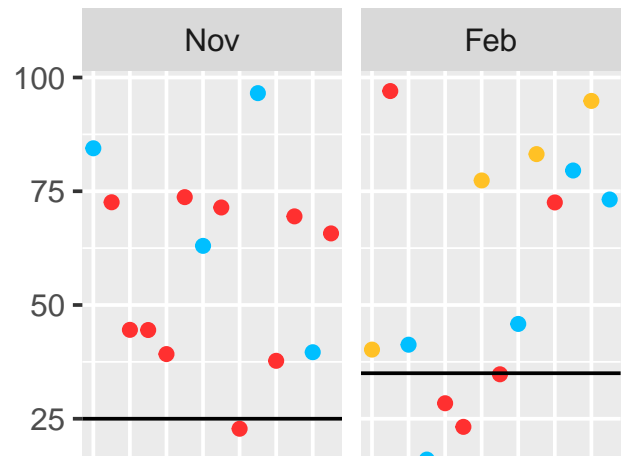

-

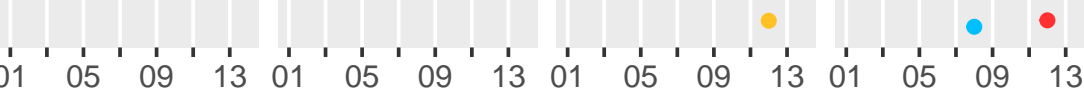
year
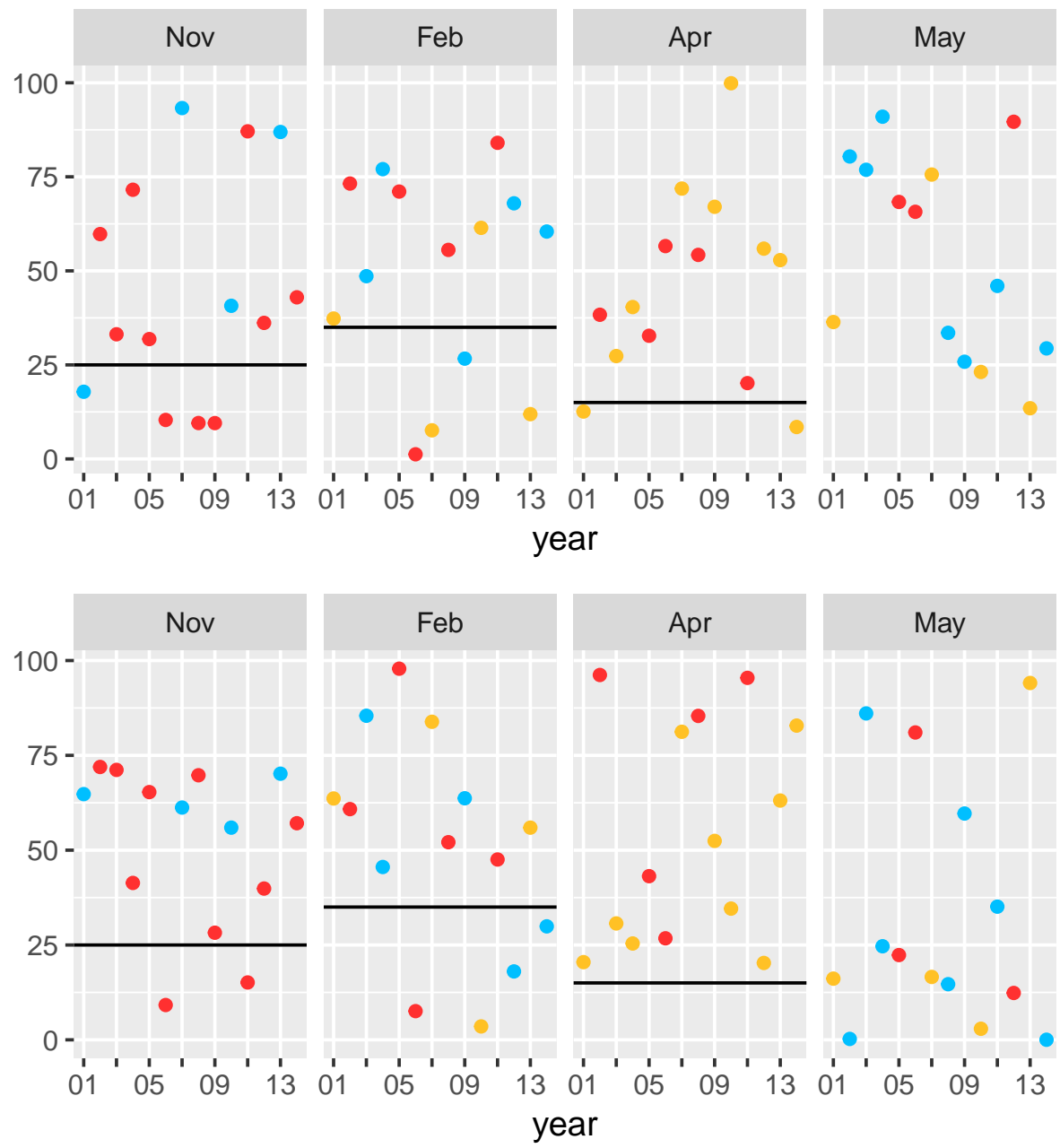

thresholds

— individual

optimal course

- poor availability

- good availability

- indifferent thresholds

— individual

optimal course

- poor availability

- good availability

- indifferent thresholds

- individual

optimal course

- poor availability

- good availability

- indifferent 
(b) Total benefit (stacked yearly values)

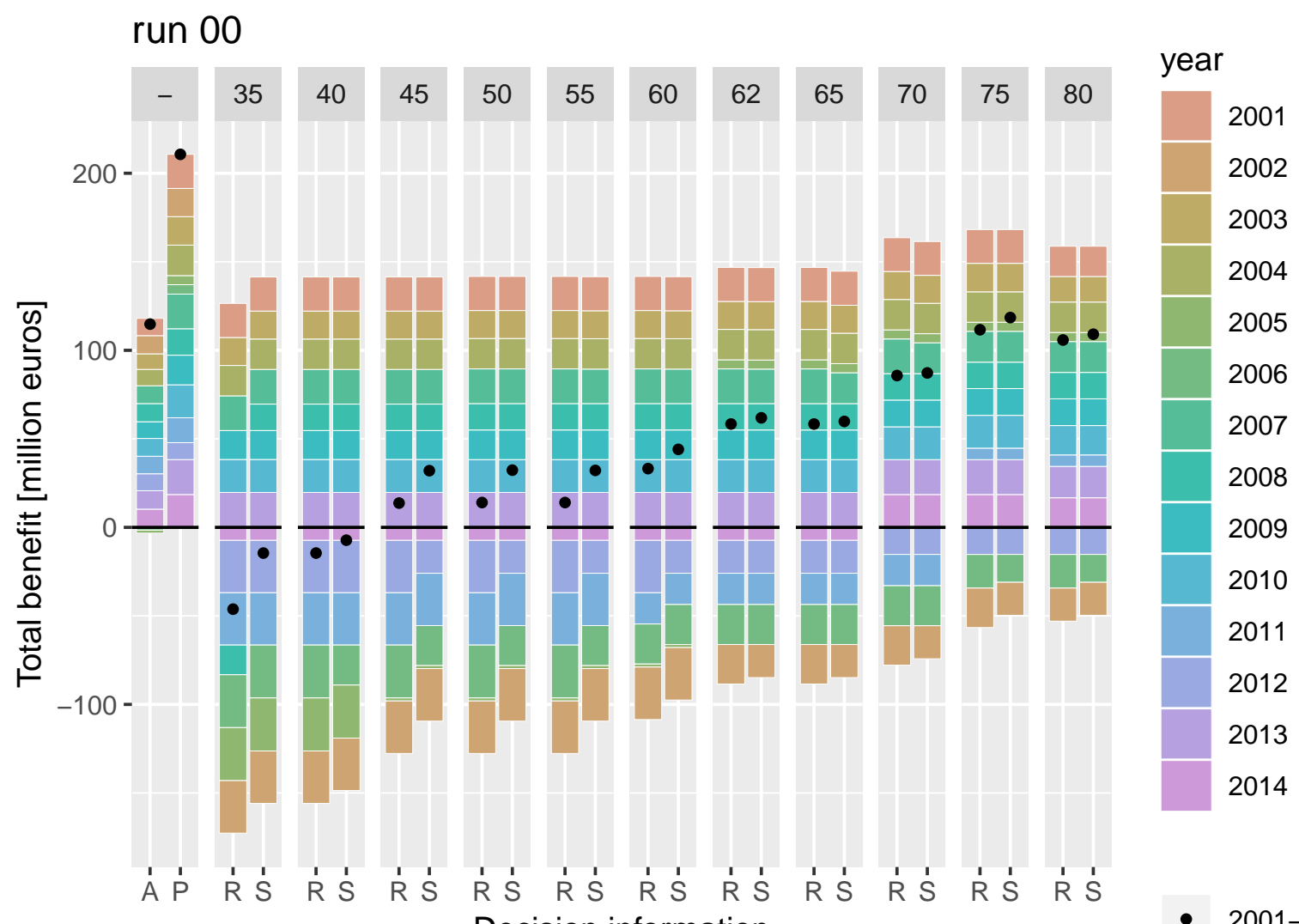

Decision information

- 2001-2014

\section{run 01}

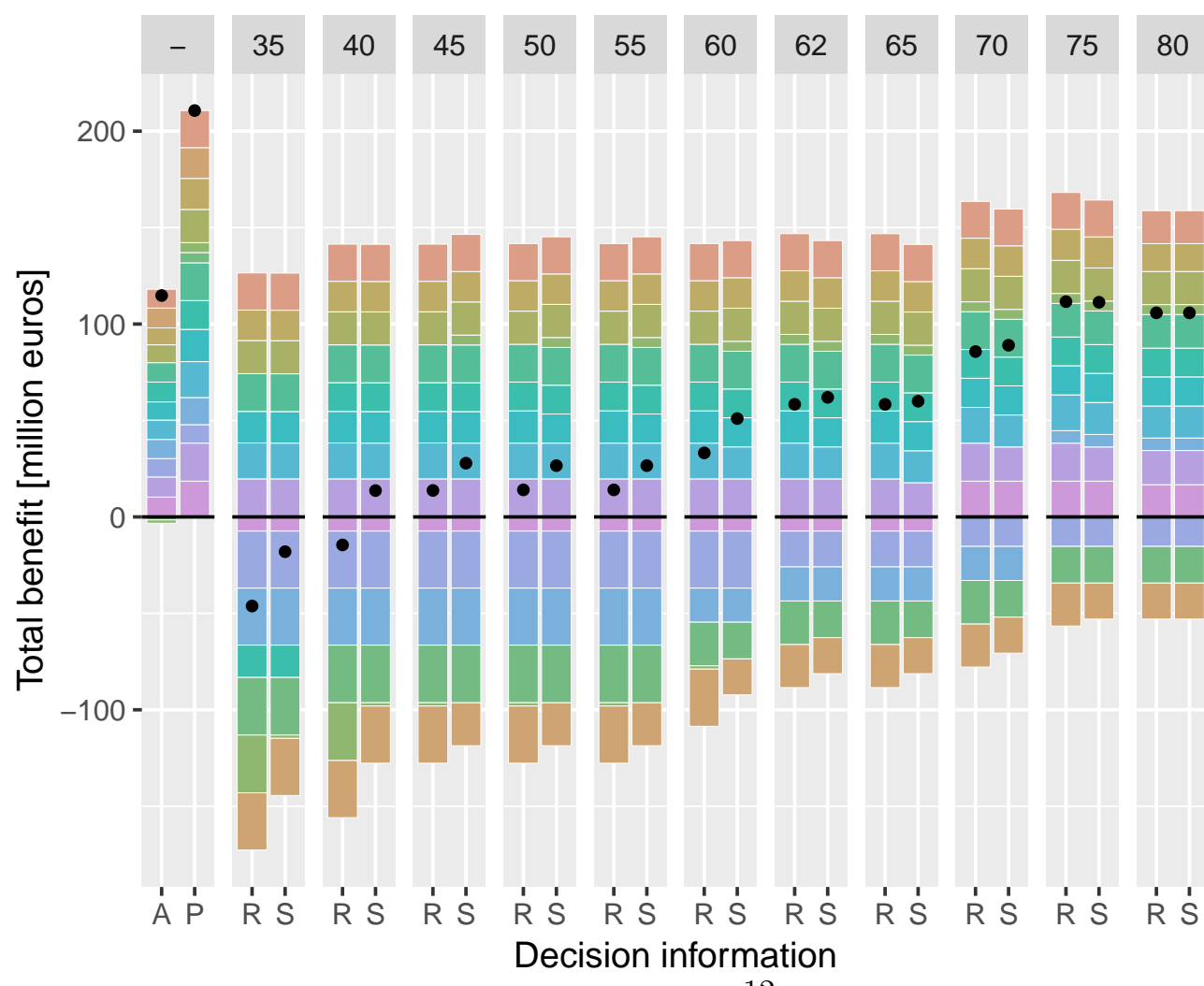

year

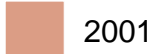

2002

2003

2004

2005

2006

2007

2008

2009

2010

2011

2012

2013

2014

- 2001-2014 


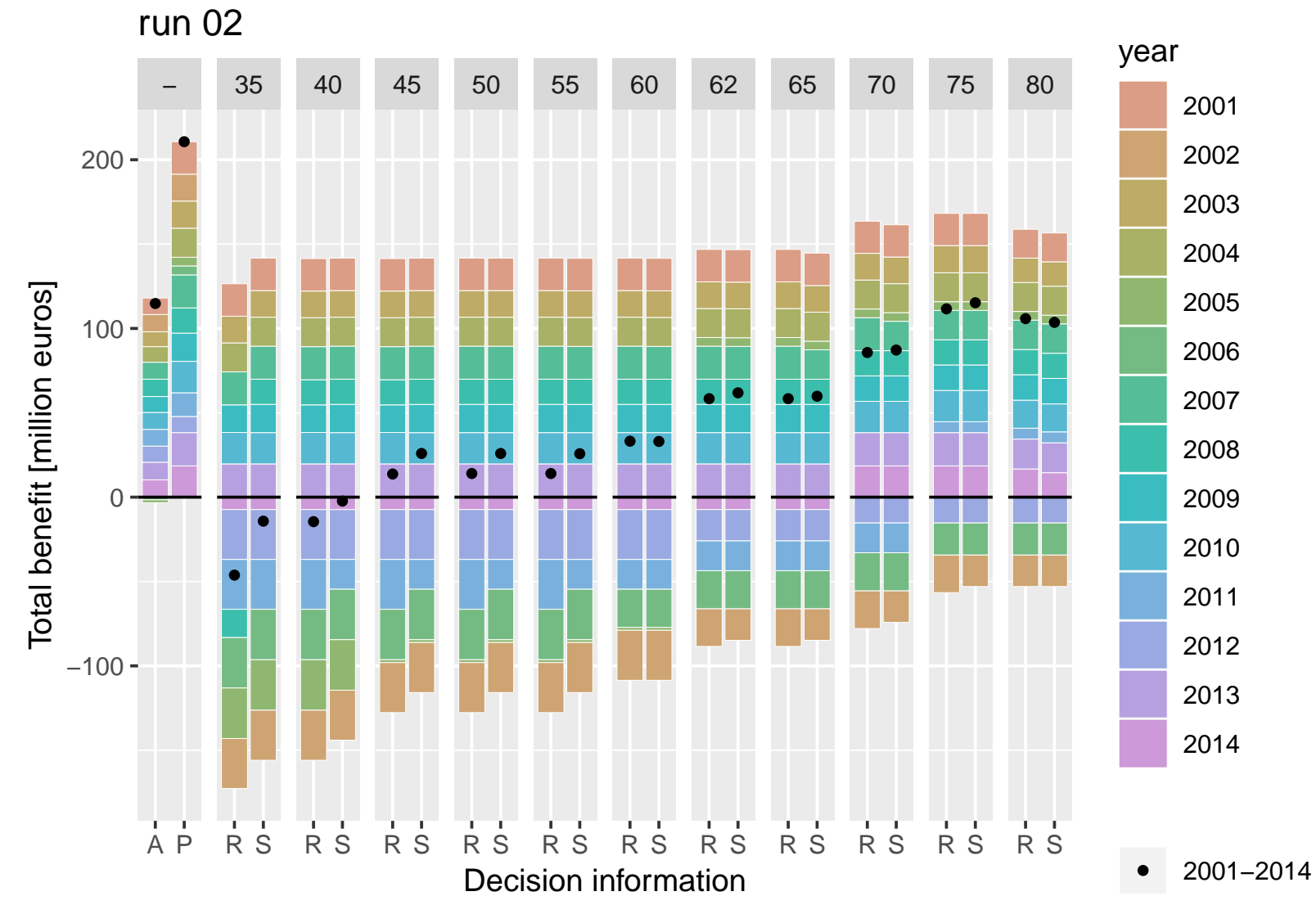




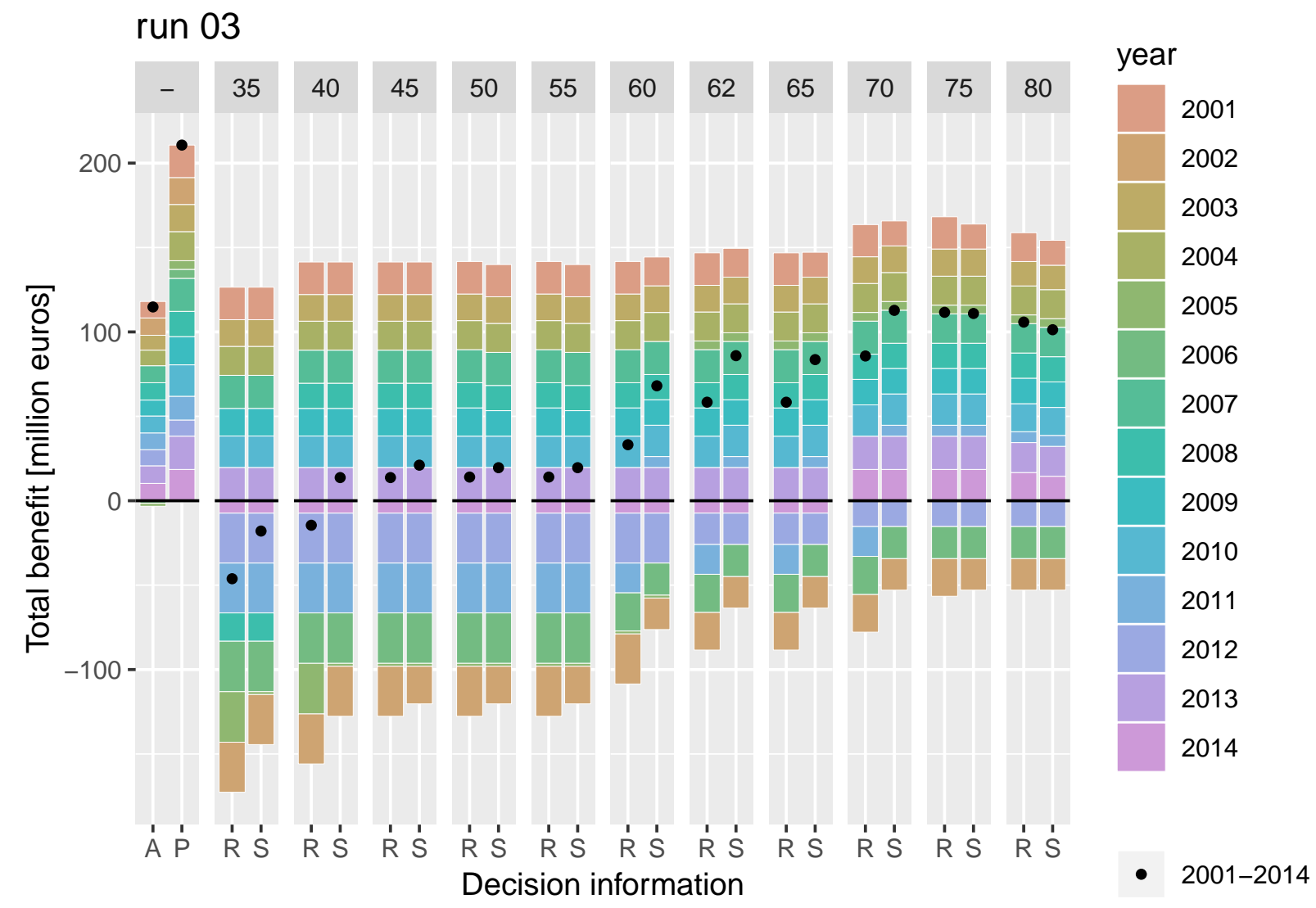




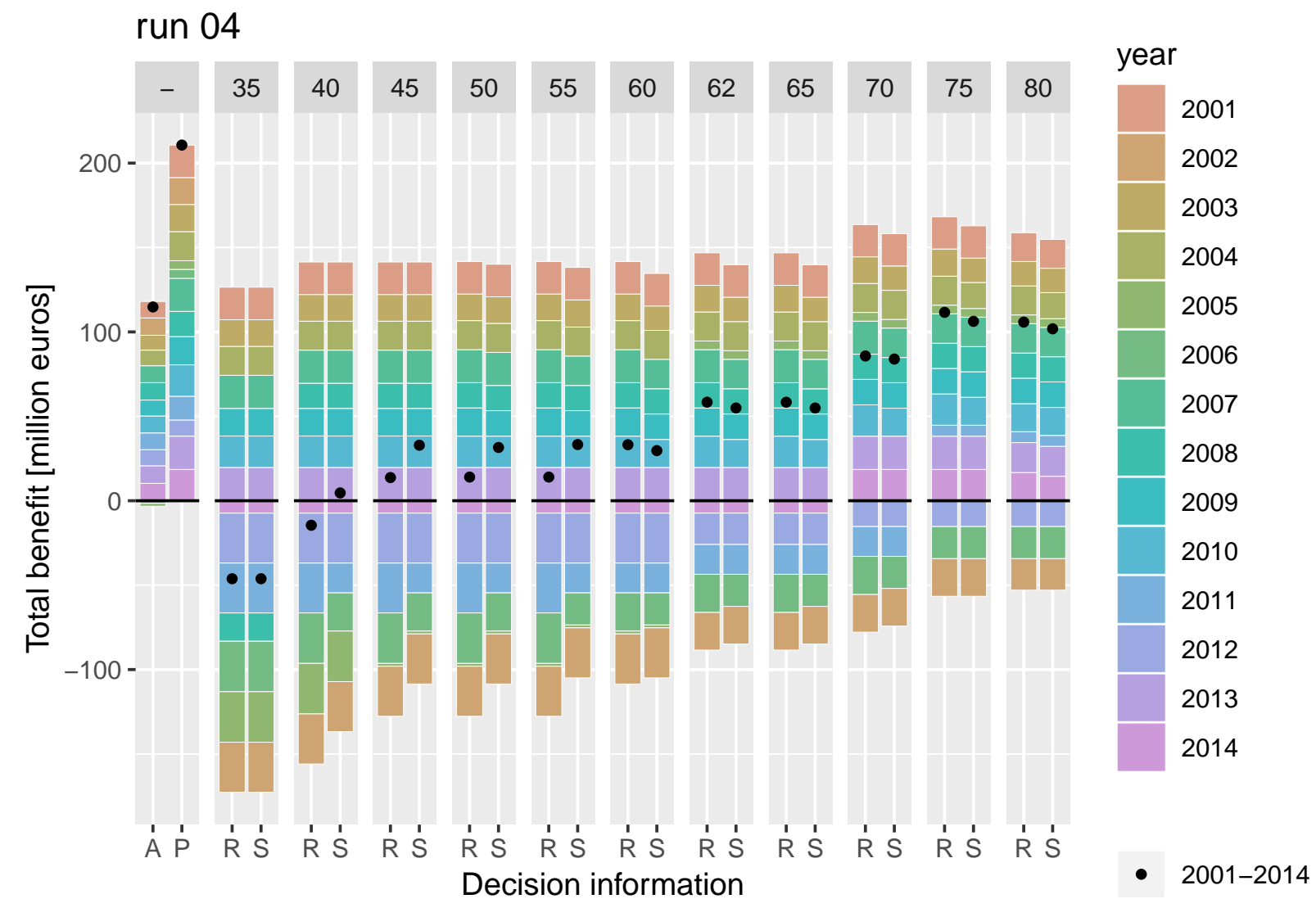




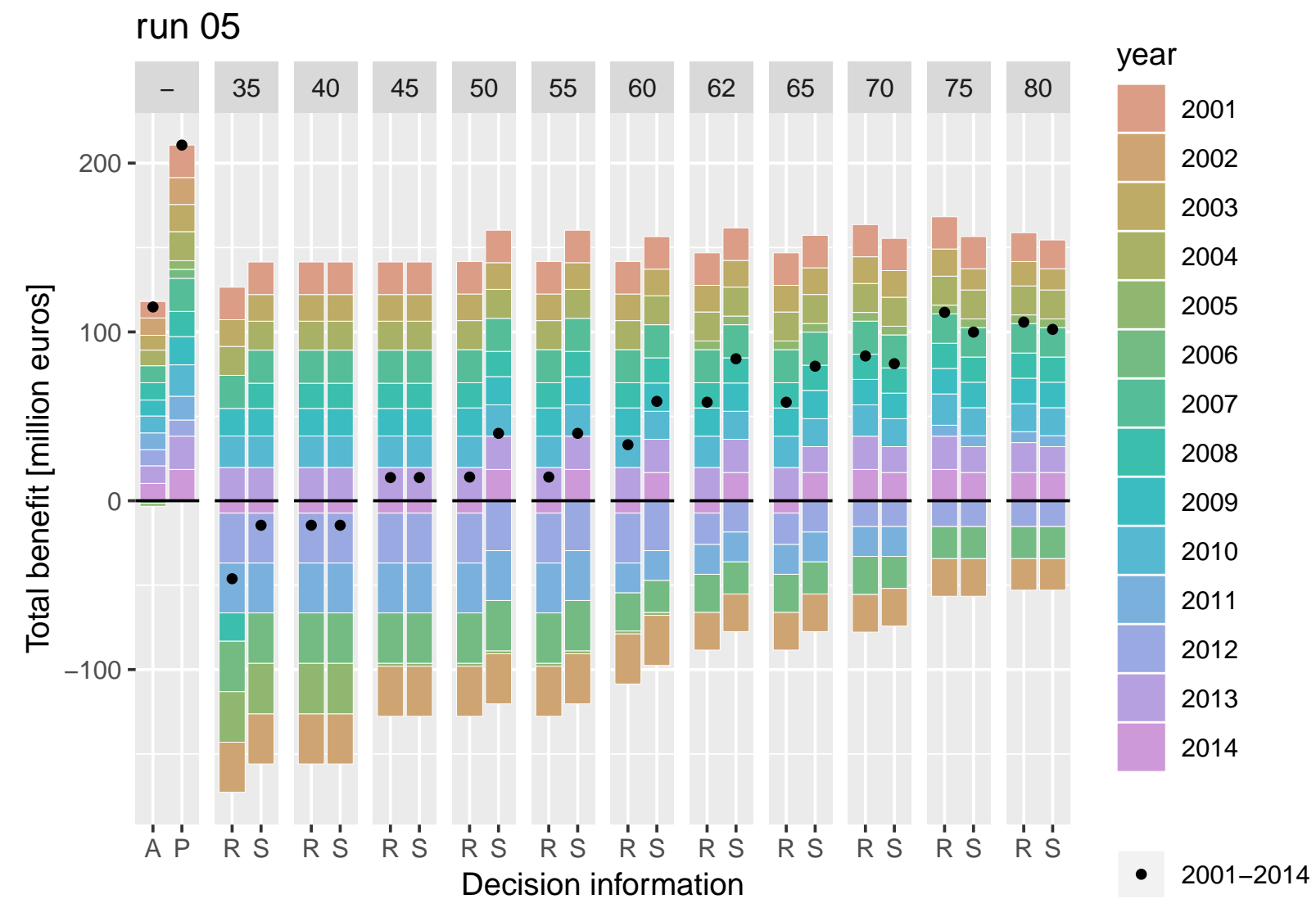




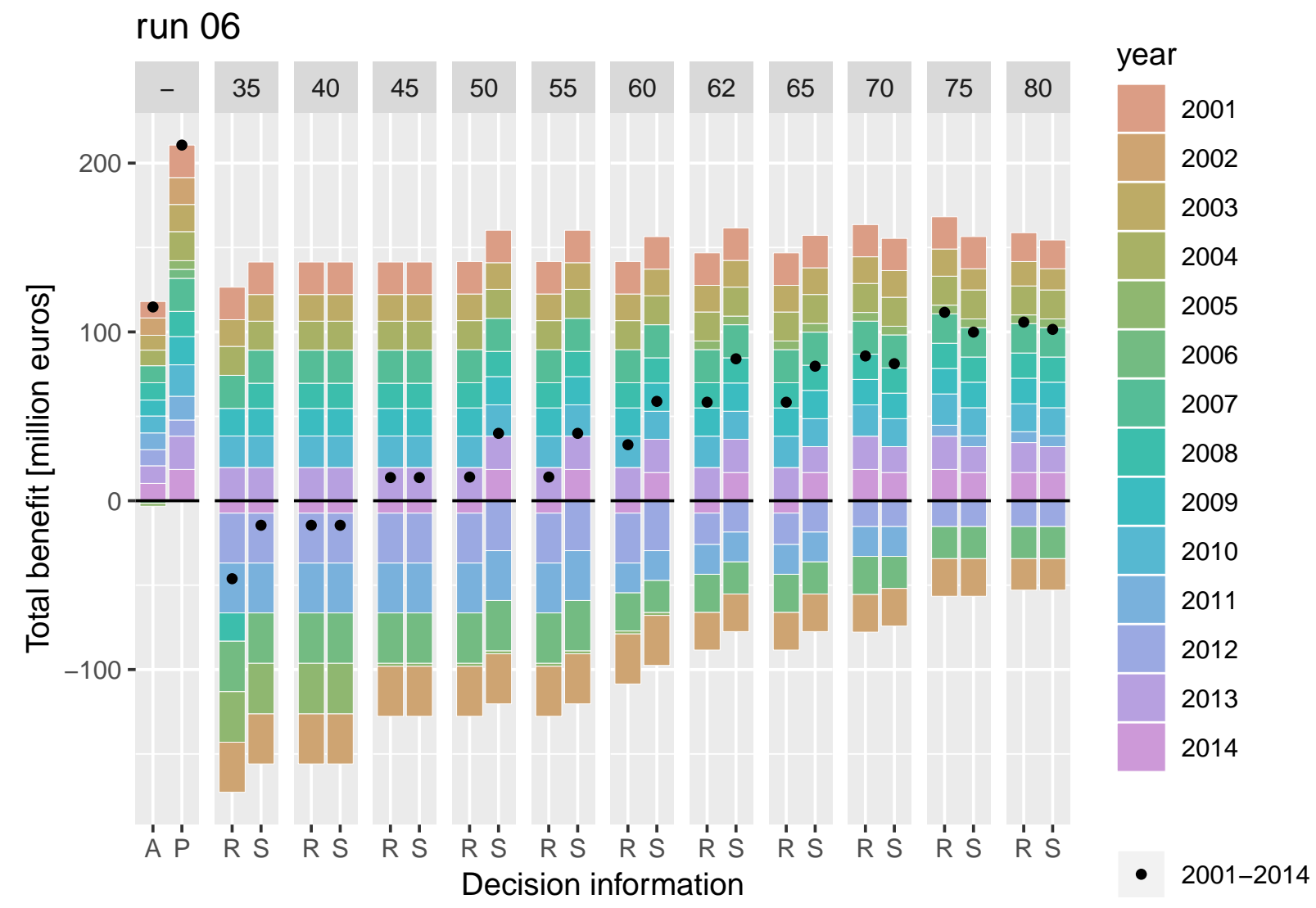




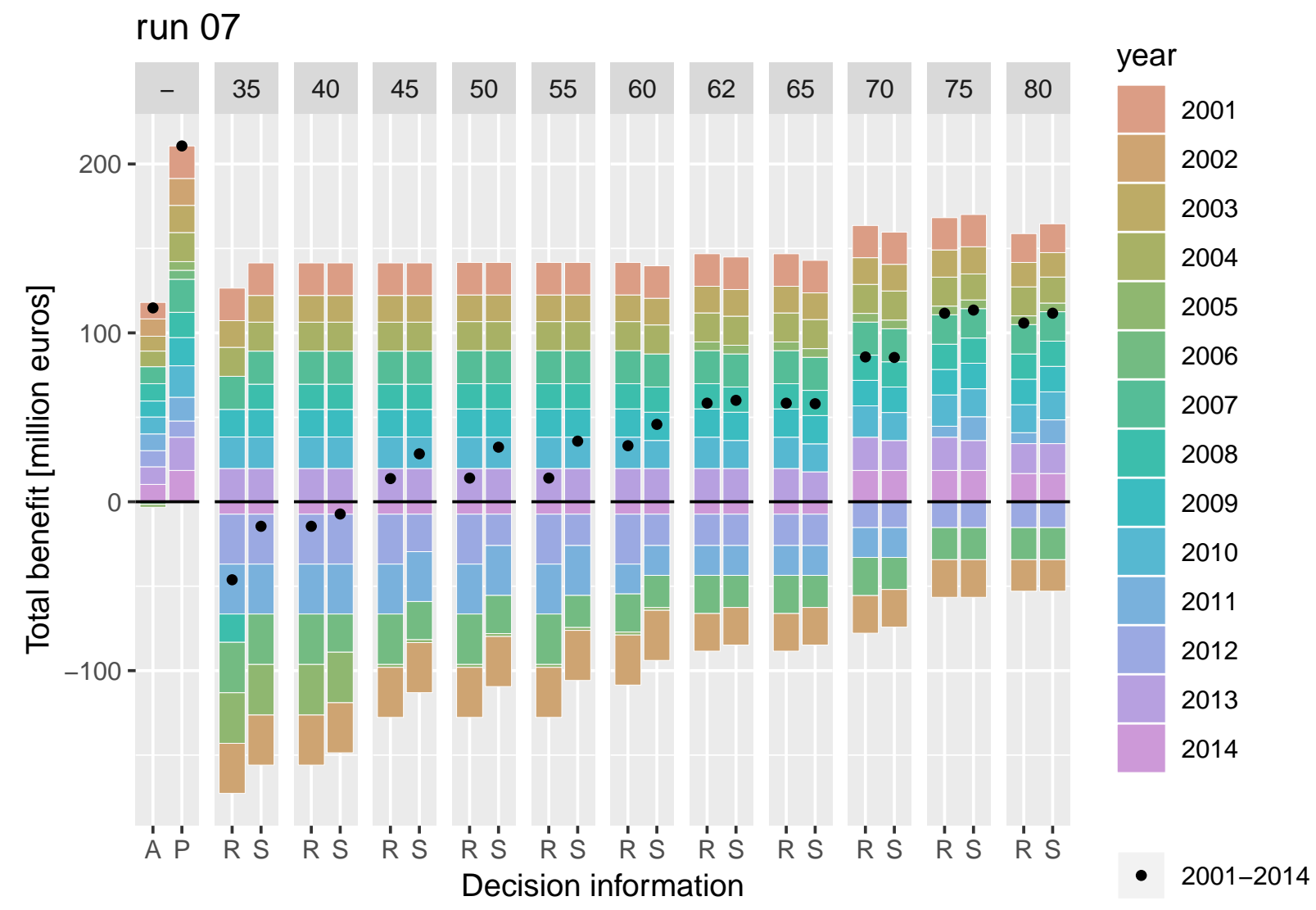




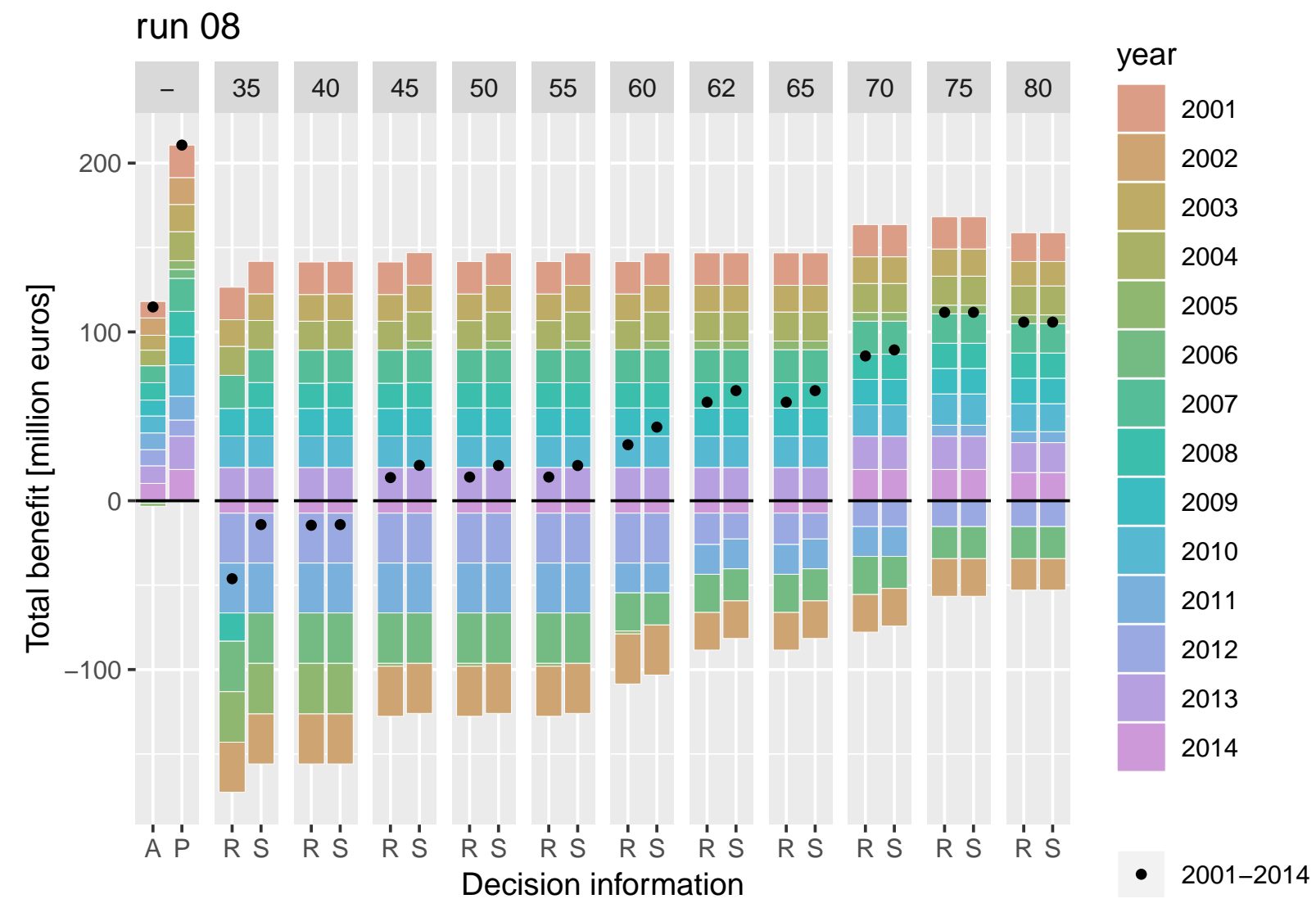




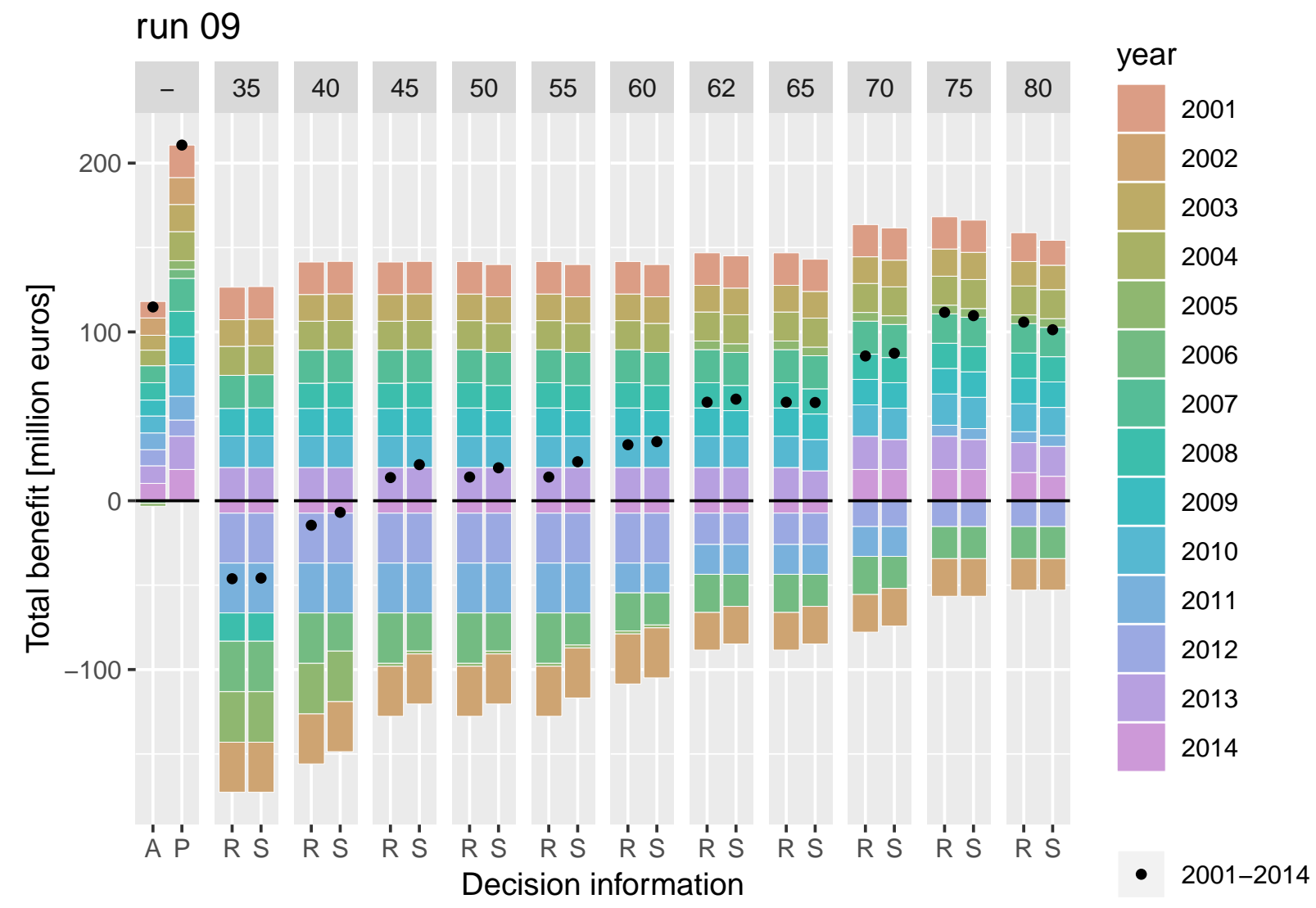




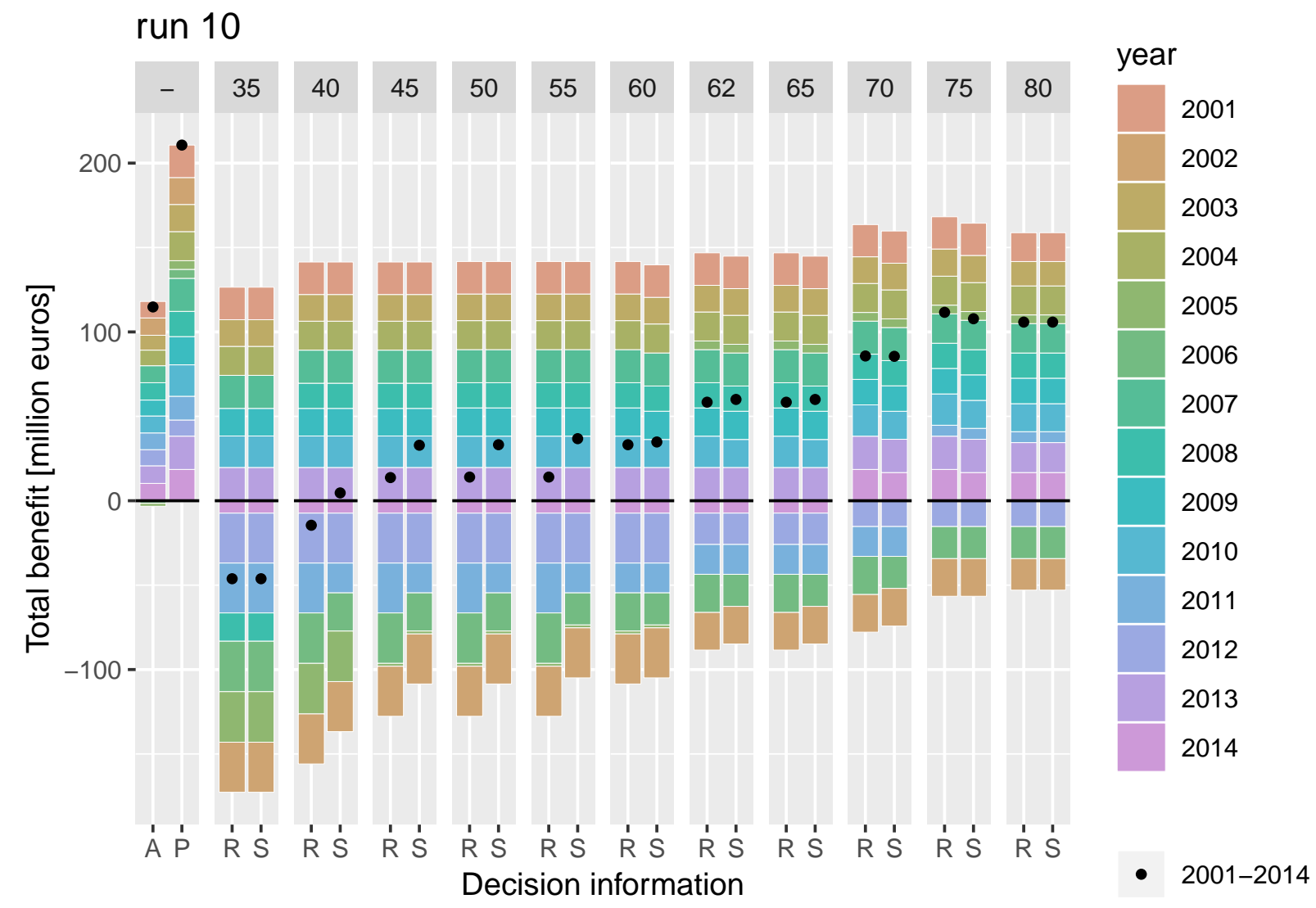

